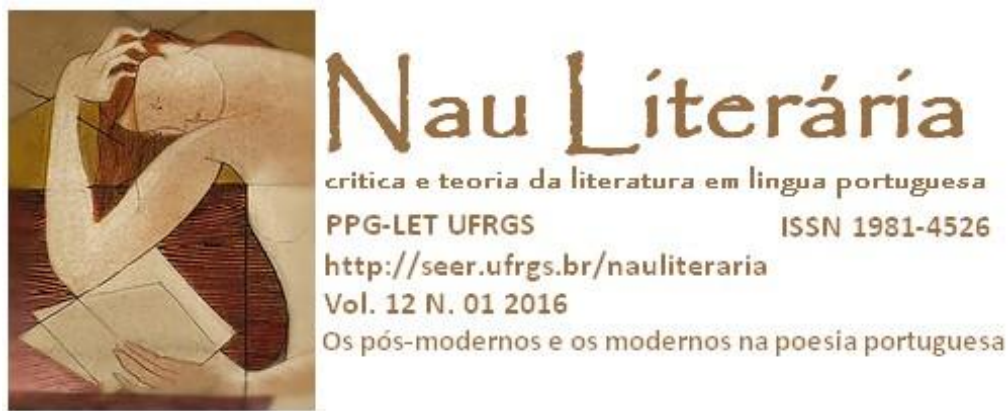

\title{
A ANGÚSTIA DA INFLUÊNCIA NAS OBRAS DE DRUMMOND, ALICE RUIZ E JUAN PABLO RIBEIRO: INTERTEXTUALIDADE, DIÁLOGO E PARÁFRASE NA BUSCA DA POESIA
}

\section{THE ANXIETY OF INFLUENCE IN THE WORKS OF DRUMMOND, ALICE RUIZ AND JUAN PABLO RIBEIRO: INTERTEXTUALITY, DIALOGUE AND PARAPHRASE IN SEARCH OF POETRY}

\author{
Lívia Petry Jahn ${ }^{1}$
}

Resumo: Este ensaio busca elucidar, como os poetas contemporâneos brasileiros, de forma bastante gritante, influenciaram uns aos outros tanto no século XX quanto no século XXI. A partir das obras de Drummond, analisaremos as obras de Alice Ruiz e Juan Pablo Ribeiro, este último, um jovem poeta do século XXI. Através de teóricos como Kristeva, Harold Bloom e T. S. Eliot, iremos discutir as noções de intertextualidade, diálogo, paráfrase, influência e a função da poesia na sociedade atual.

Palavras-chave: Influência; Intertextualidade; Paráfrase; Poesia; Diálogo.

Abstract: This essay aims to elucidate how the contemporary Brazilian poets, quite strikingly, have influenced one another in both $20^{\text {th }}$ and $21^{\text {st }}$ centuries. From the works by Drummond, we will analyze the works by Alice Ruiz and Juan Pablo Ribeiro, the latter, a young poet of the $21^{\text {st }}$ century. Being based on theorists such as Kristeva, Harold Bloom, and T. Eliot, we will discuss the notions of intertextuality, dialogue, paraphrase, influence, and the function of poetry in today's society.

Keywords: Influence; Intertextuality; Paraphrase; Poetry; Dialogue.

\section{Introdução}

Para o poeta e ensaísta T. S. Eliot, a "verdadeira poesia sobrevive não apenas à mudança da opinião pública, como também a completa extinção de interesses aos quais o poeta esteve apaixonadamente envolvido." (ELIOT, 1991, p. 36) Em seu ensaio antológico ${ }^{1}$ Pós-Doutora em Letras - Literaturas Portuguesa e Luso-Africanas pela Universidade Federal do Rio Grande do
Sul/CAPES 
sobre a função social da poesia, o bardo inglês aborda algumas questões interessantes para compreendermos a poesia como um todo, e, em especial, a poesia brasileira contemporânea.

De acordo com Eliot, a poesia teria como função primária a fruição estética, ou seja, o exercício do prazer na arte da palavra. Desta forma, o leitor seria levado a um estado de absoluto prazer na leitura do poema. Porém, a função da poesia não se resume somente a isso: na realidade, a poesia "é uma constante advertência a tudo aquilo que só pode ser dito em uma língua, e que é intraduzível”. (ELIOT, 1991, p. 37)

Neste âmbito, a poesia brasileira dos séculos XX e XXI seria uma espécie de veículo da língua portuguesa escrita e falada no Brasil, e, por isso mesmo, seria a expressão máxima da "Sensibilidade" do povo, da nação.

Seguindo os passos do poeta britânico, a poesia brasileira seria um espaço para a “comunicação de uma nova experiência, ou uma nova compreensão do familiar, ou a expressão de algo que experimentamos e para o qual não temos palavras - o que amplia nossa consciência ou apura nossa sensibilidade.” (ELIOT, 1991, p. 38). Em última instância, o papel do poeta nacional seria o de tornar-se alguém que aprimora a língua (falada e escrita) de seu povo, de seu país. Assim, ele (o poeta), é o responsável por manter a língua de sua nação cada vez mais viva e atuante.

No ensaio de Eliot, a poesia assume uma função social à medida em que ela representa o sentir, a sensibilidade de todo um coletivo. E a pergunta que nos cabe fazer, é: como ou o que sentem os brasileiros que praticam a poesia nos séculos XX e XXI? Que questões sociais, sentimentais, psicológicas e poéticas a poesia brasileira contemporânea traz até nós? Em que medida a poesia praticada por Drummond, Alice Ruiz e Juan Pablo Ribeiro tem representado a alma da nação? Tentaremos responder, ao longo deste ensaio, a estas perguntas.

\section{A Angústia da Influência e a Poesia Brasileira Contemporânea}

No entanto, se a poesia tem uma função social de "acordar" a língua, de torná-la mais "viva", o próprio fazer poético tem outros atributos. Um desses atributos se coaduna com o Cânone, e é representado pelo "rompimento" das regras do Cânone, ou pelo seu contrário, a "preservação" da literatura canônica.

Harold Bloom, em seu livro "A Angústia da Influência" (1973), nos mostra como os poetas ao longo dos séculos renovaram a escrita e a língua, ao tentar "descolar-se" da influência de poetas anteriores a eles. Bloom nos aponta o óbvio: como num movimento 
paradoxal, o poeta "novo" bebe na fonte da tradição, e, ao mesmo tempo, busca "inovar" ou seja, transgredir o movimento tradicional. Em geral, essas "transgressões" irão fazer parte do Cânone algum tempo depois, e este mesmo cânone irá sofrer uma readaptação a novos modelos.

Desta maneira, a poesia, o cânone e a língua estão em constante mutação, constante movimento. Um exemplo disso são os poetas que elencamos para estudar neste artigo: Carlos Drummond de Andrade (que faz parte do cânone brasileiro); Alice Ruiz (poeta considerada marginal, e que, com o passar do tempo, está adentrando a seara da poesia canônica) e por fim, o jovem Juan Pablo Ribeiro (poeta desconhecido do grande público, mas que faz em sua obra uma releitura do cânone brasileiro).

É interessante notar que Drummond, neste sentido, foi reescrito diversas vezes, de outras formas, em releituras poéticas bastante transgressoras em relação à ideia original do poema. A essas releituras e reescritas, chamaremos por três nomes: intertextualidade (Kristeva); Intratextualidade (Bloom); Paráfrase. Assim, teremos a Intertextualidade entendida como o diálogo entre os textos, como dois ou mais textos se interpenetram e influenciam um ao outro em suas formulações estéticas, em seus significados; a Intratextualidade ou "Relação Intrapoética" é o nome que Harold Bloom dá "aos poetas fortes quando enfrentam a tradição, quando enfrentam aos seus precursores ou antecessores, aos quais "roubam", saqueiam, mas também transfiguram ou recriam." (BLOOM apud ARCOS, 2011)

Finalmente a Paráfrase é toda a recriação de um texto, com base em outro texto (o original). Esta recriação, no entanto, se dá de forma a inovar e criar outros sentidos que o texto base não possuía. Assim, temos uma modificação da significação poética, que vai desde o uso de formas e fórmulas estéticas até a recriação de sentidos para um mesmo tipo de verso ou rima.

A partir destas formulações, apresentamos a seguir o poema de Drummond, intitulado José, seguido de duas recriações ou poemas parafrásicos, Drumondana, de autoria de Alice Ruiz; e Novamente, E agora, José? do poeta paranaense Juan Pablo Ribeiro.

José (Carlos Drummond de Andrade)

E agora, José?

A festa acabou,

a luz apagou,

o povo sumiu, 
a noite esfriou,

e agora, José?

E agora, Você?

Você que é sem nome,

que zomba dos outros,

Você que faz versos,

que ama, protesta.

E agora, José?

Está sem mulher,

Está sem discurso,

Está sem carinho,

Já não pode beber,

Já não pode fumar,

Cuspir já não pode,

A noite esfriou,

O bonde não veio,

$\mathrm{O}$ riso não veio,

Não veio a utopia

E tudo acabou

E tudo fugiu

E tudo mofou,

E agora, José?

E agora, José?

Sua doce palavra,

Seu instante de febre,

Sua gula e jejum,

Sua biblioteca,

Sua lavra de ouro,

Seu terno de vidro,

Sua incoerência,

Seu ódio - e agora?

Com a chave na mão

Quer abrir a porta,

Não existe porta,

Quer morrer no mar,

Mas o mar secou;

Quer ir para Minas,

Minas não há mais. 
José, e agora?

Se você gritasse,

Se você gemesse,

Se você tocasse,

A valsa vienense,

Se você dormisse,

Se você cansasse,

Se você morresse...

Mas você não morre,

Você é duro, José!

Sozinho no escuro

qual bicho do mato,

sem teogonia,

sem parede nua

para se encostar,

sem cavalo preto

que fuja do galope,

você marcha, José!

José, para onde?

Neste poema claramente distópico, Carlos Drummond de Andrade mostra todo o seu desencanto e amargura de homem do século XX. Lembremos que Drummond viveu os horrores da Segunda Guerra Mundial e, depois, da Guerra Fria. Adepto ao comunismo, também sofreu a desilusão do socialismo totalitário no Bloco Comunista (Europa Oriental e a extinta União Soviética). A perda das ilusões, a perda das utopias, o vazio existencial, político e social, a crise do homem contemporâneo, tudo isto é retratado no poema José. Drummond é provocativo, a começar pelo título da sua obra: José é o nome bíblico de um personagem que, após ser cativo no Egito, se torna Governador do Faraó. E, seguindo a linhagem bíblica, é também o nome do homem devoto que cria Jesus Cristo como seu filho. Por estas duas razões, este nome bíblico tornou-se símbolo de nome cristão, espalhou-se pelos filhos de Portugal, mais tarde pelos filhos do Brasil, e dessa maneira se tornou o nome mais conhecido e popular dos dois países. Drummond, utiliza-se portanto, de um nome extremamente popular, comum, e que tem representatividade no povo desta nação. Assim, intitulando o poema e o eu-lírico de José, o poeta faz uma clara homenagem ao povo brasileiro. 
Em seguida, o poeta, num tom pessimista, vai elencando o final de uma era: "a festa acabou, a luz apagou, o povo sumiu, a noite esfriou", para em seguida, surgir com a pergunta que permeia todas as estrofes: "E agora, José?"

José, o personagem do poema, é desprovido de tudo o que possa dar sentido à sua existência: “está sem mulher, está sem discurso, está sem carinho, já não pode beber, já não pode fumar, cuspir já não pode [...]". Tudo lhe é retirado ou proibido. E, para piorar o vazio de sua existência, ele perde o ritmo da vida, ele já não sabe mais o que fazer, ou para onde ir, pois: "o bonde não veio, o riso não veio, não veio a utopia, e tudo acabou, e tudo mofou."

A ele é dado o fardo de uma vida sem sentido para a qual não há escapatória, pois nem morrer, ele morre, como diz o eu-lírico: "Mas você não morre, você é duro, José!” A liberdade do personagem é uma razão amarga, sem Deus, "sem teogonia", sem amparo de nada ou ninguém. Esta é uma razão profunda do existir sem que haja um propósito para isso, sem que se saiba o porquê de estar vivo.

A toda essa amargura se coaduna uma certeza: "você marcha, José!" E um questionamento: “José, para onde?" - E eis que num único poema, Drummond coloca as três perguntas básicas da vida humana: "De onde viemos? Quem somos? Para onde vamos?"

E, claro, além de fazer deste um poema existencialista per se, Drummond também atinge o âmago das questões políticas de seu tempo e da era contemporânea, ou seja, o fim das utopias e o surgimento de um mundo sem valores e sem regras claras no jogo da política, seja no Brasil, seja no Mundo.

Tomaremos, portanto, o poema de Drummond como o texto base de dois outros poemas. Se, para Alice Ruiz, em seu texto, tudo é subvertido e José se transforma em Maria, para Juan Pablo Ribeiro, José padece de amores não correspondidos. Assim, Juan Pablo reescreve e relê a Drummond:

Novamente, e agora José?

José como todos os outros

Também tem um amor

Platônico.

Mas diferente d'outros

O seu é Helena.

Helena o amou antes

De ser o amor real

De Carlos, e agora José? 
Neste poema, não há distopia, mas há toda uma ironia que perpassa os seus versos. José é e não é real, José (o alter ego de Drummond), disputa com o poeta o amor de Helena. Ficção e realidade se misturam, e, ambos os personagens (um real, e outro fictício) criam um triângulo amoroso com uma terceira personagem (desta vez real e mítica ao mesmo tempo). Helena tem seu nome escolhido de propósito, pois remete à Helena de Troia (rainha e personagem mítica dos Gregos) conhecida por sua beleza incomparável. Assim, o poema, que termina com o verso de Drummond: “e agora, José?”, faz uma releitura irônica e romântica de trechos do poema do bardo itabirano, quando Drummond confessa: “está sem mulher, está sem discurso, está sem carinho". Juan Pablo reescreve a história de José sob outro viés: não mais o vazio das utopias, da existência, mas dos afetos. E assim, através da junção do mito (Helena) com a ficção (José) e a realidade (Carlos), Juan Pablo ressignifica e faz uma releitura do poema canônico de Drummond. Temos aqui tanto o "rompimento" com o cânone quanto a reinvenção deste mesmo cânone, através da paráfrase, da intertextualidade e da intratextualidade poética. Juan Pablo "bebe na fonte", o texto base José. Ele se apropria do texto base, reelabora-o e dá outro sentido para o José do poema de Drummond (intratextualidade poética). Ambos os poemas se relacionam e dialogam entre si (intertextualidade), ao passo que, no poema “Novamente, e agora José?”, a obra do poeta mineiro se vê significada e escrita de outra forma (paráfrase), dando lugar a uma visão romântica da vida, onde o triângulo amoroso é o que se sobrepõe à existência.

Já na releitura de Alice Ruiz, o poema de Drummond é completamente modificado. José muda de nome e gênero: chama-se Maria. A poeta paranaense deixa com que permaneçam as mesmas formas poéticas, o uso de verbos no passado, a pergunta de sempre: “E agora, Maria?”, além de recriar outros sentidos para o vazio existencial da personagem. Se José perdeu o bonde e a utopia, Maria perdeu o amor, os filhos, o marido. Leiamos:

\section{Drumondana (Alice Ruiz)}

E agora, Maria?

O amor acabou,

A filha casou,

O filho mudou,

Teu homem foi pra vida

Que tudo cria

A fantasia

Que você sonhou

Apagou 
À luz do dia,

E agora, Maria,

Vai com as outras,

Vai viver

Com a hipocondria.

Por um lado, temos já no título uma ironia: a homenagem a Drummond, e, ao mesmo tempo, a junção com a palavra "mundana" - ou seja, aquilo que pertence essencialmente ao mundo - em oposição à ideia de "alma", espírito, ou essência do ser. Num tom bastante amargo e igualmente distópico, e, nesse sentido, seguindo o tom e o ritmo do poema base, José, Alice Ruiz desconstrói os mitos e as utopias femininos: a mãe sofre a perda inevitável dos filhos quando estes se tornam adultos, o amor acaba, o casamento se desfaz... E as fantasias sonhadas não resistem à luz do dia. Resta apenas, tornar-se uma "doente crônica", resta a hipocondria, que a torna igual a tantas outras mulheres na mesma situação. Mesmo terminando de forma triste e irônica, o poema de Ruiz retrata muito bem a situação real de muitas mulheres no Brasil, e, quiçá, em outras partes do mundo.

Se Drummond falava da crise existencial de um homem, José, Alice Ruiz trata do mesmo tema só que transportado para o gênero feminino e suas questões mais básicas. Assim, ambos os textos dialogam (intertextualidade) através de uma visão amargurada da existência, dos sonhos (utopias) desfeitos, das tantas frustrações que a vida apresenta, da incapacidade de lidar com a realidade e sem poder evitar a vida ("Mas você não morre, José!" / "Vai viver com a hipocondria") e o cotidiano absurdo de uma existência vazia de sentido.

Por outro lado, Alice Ruiz reinventa e dá outras conotações à poesia de Drummond, porém mantém a mesma estrutura rítmica e poética (intratextualidade poética). E, finalmente, ela cria um sentido próprio, transpondo para a sua escrita traços do poeta mineiro, sem, no entanto, imitar ipsis litteris o texto base, mas dando a ele uma nova leitura/escrita (paráfrase).

Através desse exemplo, podemos constatar como a tradição influencia poetas que, sendo contemporâneos, ao mesmo tempo em que se servem do cânone como modelo, o reinventam à sua maneira. Juan Pablo Ribeiro, poeta jovem, da cidade de Guarapuava, Paraná, nos brinda com esta pérola:

\section{Currículo Poético (Juan Pablo Ribeiro)}

Eu sei andar nas estrelas

E tropeçar nas nuvens. 
Correr com luz

Nos labirintos.

Sei afinar os pássaros

De acordo com os

Acordes que vão nas

Tablaturas cristalinas

Dos olhos alheios.

Sei flutuar na nuance

Do descaso como folha

Que veste o vento com

Calma. Sei desenhar

Com os olhos, como sei

Sonhar com as pernas.

Como foi dito antes, a língua se renova através da poesia, e o poeta tem a função social de manter viva e atuante a língua de seu povo, de seu país. Assim, um jovem e bom poeta, nada mais é do que um arauto da vida, alguém que traz para dentro da poesia de língua portuguesa outras nuances, outras significações. Se Fernando Pessoa tropeçava "no tapete das etiquetas", Juan Pablo Ribeiro tropeça nas nuvens. Feito Teseu, ele enfrenta labirintos, onde corre com luz. E fosse o poeta o maestro supremo, ele afina os pássaros com os acordes de olhares alheios. Nada nele é tangível, palpável, mas tudo nele é sensível, como a folha e o vento, uma vestindo o outro. E, se o poeta, acaso se corporifica, é para sonhar.

Se temos em Drummond uma espécie de "espelho poético" para onde nos dirigir, em Juan Pablo Ribeiro temos a continuidade da tradição. Só que renovada. Assim, leiamos duas estrofes do poema abaixo:

Poema das Sete Faces (Carlos Drummond de Andrade)

Quando nasci, um anjo torto

Desses que vivem na sombra

Disse: Vai, Carlos! Ser gauche na vida.

$[\ldots]$

Eu não devia te dizer

Mas essa lua,

Mas esse conhaque,

Botam a gente comovido como o diabo.

E, em seguida, leiamos o poema de Juan Pablo Ribeiro: 
Vidinha Triste (Juan Pablo Ribeiro)

Regalou-se meu corpo nesta embarcação chorosa,

O colo de minha mãe,

Ah, os olhos úmidos dela.

Quando pela primeira vez

Esfregaram-se nesta existência tênue,

Pequenina.

Esta existência de mar.

O colo de minha mãe: barco alçado em velas brancas

(E amarelas);

Barco em mastros e falhas saídos dos lábios de meu pai.

E assim, singrando mares, caí na terra.

Caí na ferramenta da arte.

Caí na vida.

A noite foi minha primeira mulher, a mais fiel,

Ancorei meus olhos nas palavras,

Ofeguei quando cresci,

Meu vigor ficou bêbado,

Meu ar pegou café e foi fumar.

Em Drummond, temos todo um inventário de uma vida desde o nascimento (com um anjo torto dizendo que o poeta será igualmente gauche - torto em francês - mas que também significa à esquerda) até o momento em que o poeta, de posse de um conhaque, deixa-se abater pela comoção. Já no poema de Juan Pablo, o nascimento se iguala a existir no mar, numa embarcação frágil (a mãe) e depois de singrar os mares, ele subitamente cai na terra. Essa queda se dá de várias formas: na solidão que o poeta sente (a noite foi minha primeira mulher, a mais fiel), na arte das palavras, no vigor bêbado, no café, no cigarro. Como na poesia de Drummond, este poema também se inicia pelo nascimento e termina num copo de conhaque. Enfim, podemos distinguir nos dois poetas toda uma sensibilidade que os iguala (enquanto bardos) e os diferencia da maior parte da sociedade ao mesmo tempo. Essa 
sensibilidade é que leva-os a transgredir as regras gramaticais, a renovar a arte da poesia, a tornar cada vez mais vívida, a língua portuguesa.

\section{Conclusão}

Respondendo às questões do início deste artigo, são poetas como Drummond, Alice Ruiz e Juan Pablo Ribeiro, que fazem a diferença dentro de um processo de civilização e leitura/escrita no Brasil.

Cada um dos bardos elencados acima tem um papel fundamental na história da literatura brasileira, sejam eles conhecidos ou não. $O$ importante, aqui, não é o (re)conhecimento, mas o quanto aquele poeta auxiliou na renovação da literatura e da língua portuguesa.

Ao trazer outras imagens, outras formas de escrita, outras significações, o poeta jovem realiza uma leitura própria do cânone, uma leitura "antropofágica", onde ele "deglute" a poesia de seus antecessores e a devolve reinterpretada de outra maneira. Assim, temos, como queria Bloom, o eterno retorno ao cânone junto de sua eterna renovação.

Finalizando, podemos dizer que, a partir do século XX, a poesia brasileira sofreu uma radical transformação e pôde gerar, desta maneira, toda uma revitalização do seu cânone. Junto a isto, temos o surgimento de poetas "marginais" na década de 1970 e de poetas desconhecidos na década de 2000. Tais poetas, como Alice Ruiz e Juan Pablo Ribeiro, mesmo tendo passado por diferentes vertentes e épocas (Alice produziu sobretudo haicais na década de 1970 e Juan Pablo produziu sua melhor poesia entre 2013 e 2015), e, mesmo estando "à margem" do cânone, têm renovado o fazer poético brasileiro, e, só por este fato, já devem ser mencionados e mais bem conhecidos do público. Eis o propósito deste artigo, fazer com que você, caro leitor, conheça mais e melhor o que se produz no seu país, na sua língua, e que, segundo Eliot, é “absolutamente intraduzível” para outro idioma.

\section{REFER*ENCIAS}

ANDRADE, Carlos Drummond de. Poesia completa. Rio de Janeiro: Nova Aguilar, 2002.

BLOOM, Harold. Harold Bloom, el canon, la angustia de las influencias. Disponível em $<$ www.estudiosliterariosunrn.wordpress.com >.Acessado em 29/04/2017.

ELIOT, T. S. A função social da poesia: de poesia e poetas. São Paulo: Brasiliense, 1991. KRISTEVA, Julia. História da linguagem. Lisboa: Edições 70, 2007. 
RIBEIRO, Juan Pablo Ramos. Diálogo dos olhos. Lisboa: Chiado, 2015.

RUIZ, Alice S. Dois em um. São Paulo: Iluminuras, 2008. 